\begin{tabular}{|c|c|c|c|}
\hline & Rheumatology $n=61$ & Oncology $n=13$ & Total $n=74$ \\
\hline \multicolumn{4}{|c|}{$\begin{array}{l}\text { How familiar are you with ICI used for the treatment of cancer (for instance, anti-CTLA-4 } \\
\text { ipilimumab, and anti-PD-1, nivolumab)? }\end{array}$} \\
\hline Totally unfamiliar, $n(\%)$ & $7(11.5)$ & $0(0.0)$ & $7(9.5)$ \\
\hline $\begin{array}{l}\text { I have heard of them, but am } \\
\text { not familiar, } n(\%)\end{array}$ & $39(63.9)$ & $0(0.0)$ & $39(52.7)$ \\
\hline Somewhat familiar, $n(\mathbf{X})$ & $11(18.0)$ & $1(7.7)$ & $12(16.2)$ \\
\hline Moderately familiar, $n(\%)$ & $4(6.6)$ & $7(53.8)$ & $11(14.9)$ \\
\hline Totally familiar, $\mathrm{n}(\mathbf{X})$ & $0(0.0)$ & $5(38.5)$ & $5(6.7)$ \\
\hline \multicolumn{4}{|c|}{ Are you aware that ICI can cause rheumatic irAE? } \\
\hline Yes, $n(\%)$ & $52(85.2)$ & $13(100)$ & $65(87.8)$ \\
\hline No, $n(\%)$ & $6(9.8)$ & $0(0.0)$ & $6(8.1)$ \\
\hline No answer, $n(\%)$ & $3(4.9)$ & $0(0.0)$ & $3(4.1)$ \\
\hline \multicolumn{4}{|c|}{$\begin{array}{l}\text { Do you have any patient treated with ICI (namely, anti-CTLA-4, ipilimumab, or anti-PD-1 } \\
\text { nivolumab) who developed a rheumatic irAE? }\end{array}$} \\
\hline Yes, $n(\%)$ & $3(4.9)$ & $6(46.2)$ & $9(12.2)$ \\
\hline No, $n(\%)$ & $36(59)$ & $6(46.2)$ & $42(56.7)$ \\
\hline $\begin{array}{l}\text { I have no patient treated with } \\
\text { such drugs, } n(\%)\end{array}$ & $19(31.1)$ & $1(7.7)$ & $20(27)$ \\
\hline No answer/do not know, n(\%) & $3(4.9)$ & $0(0.0)$ & $3(4.1)$ \\
\hline \multicolumn{4}{|c|}{ If you answered "yes" to the previous question, what type of rheumatic irAE was it? } \\
\hline Arthralgia, $n(\$ 8)$ & $2(66.7)$ & $3(50.0)^{*}$ & $5(50.0)$ \\
\hline 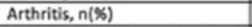 & $1(33.3)$ & $1(16.7)$ & $2(20.0)$ \\
\hline Myositis, $n(\%)$ & $0(0.0)$ & $1(16.7)$ & $1(10.0)$ \\
\hline Sicca syndrome, $n(\%)$ & $0(0.0)$ & $1(16.7)^{*}$ & $1(10.0)$ \\
\hline Vasculitis, $\mathrm{n}(\%)$ & $0(0.0)$ & $0(0.0)$ & $0(0.0)$ \\
\hline Other, $n(\mathbf{s})$ & $0(0.0)$ & $1(16.7)$ & $1(10.0)$ \\
\hline \multicolumn{4}{|c|}{$\begin{array}{l}\text { Do you believe there is benefit in a multidisciplinary Rheumatology-Oncology approach } \\
\text { allowing timely assessment and referral of patients who develop rheumatic irAE? }\end{array}$} \\
\hline Yes, $n(\%)$ & $56(91.8)$ & $11(84.6)$ & $67(90.5)$ \\
\hline No, $n(\$)$ & $1(1.6)$ & $1(7.7)$ & $2(2.7)$ \\
\hline No answer/do not know, n(\$) & $4(6.6)$ & $1(7.7)$ & $5(6.8)$ \\
\hline \multicolumn{4}{|c|}{ What are your educational needs on rheumatic irAE?" } \\
\hline $\begin{array}{l}\text { Pathophysiologic and } \\
\text { immunologic principles, } n(\%)\end{array}$ & $7(11.5)$ & $0(0.0)$ & $7(7.9)$ \\
\hline $\begin{array}{l}\text { Epidemiology and clinical } \\
\text { features, } n(\boldsymbol{*})\end{array}$ & $8(13.1)$ & $0(0.0)$ & $8(9.1)$ \\
\hline $\begin{array}{l}\text { Assessment and treatment, } \\
n(\%)\end{array}$ & $19(31.1)$ & $5(38.5)$ & $24(27.3)$ \\
\hline All of the above, $n(\%)$ & $41(67.2)$ & $8(61.5)$ & $49(55.7)$ \\
\hline
\end{tabular}

Abstract AB1386 - Figure 1

Conclusions: Most rheumatologists had limited knowledge of $\mathrm{ICl}$ and limited experience with rheumatic irAE, compared to oncologists. Both groups considered that the development of multidisciplinary teams would be beneficial to allow timely assessment and referral of these patients. Despite limited by the response rate (particularly low for oncologists) and response bias, this study emphasises the need for specific education on $\mathrm{ICl}$ and irAE, especially for Portuguese rheumatologists.

Disclosure of Interest: None declared

DOI: 10.1136/annrheumdis-2018-eular.3831

\section{AB1387 ACKNOWLEDGED BIOSTATISTICAL HELP AND THE QUALITY OF STATISTICAL ANALYSES IN RANDOMISED CONTROLLED TRIALS IN RHEUMATOLOGY}

G. Guzelant, E. Dincses, G. Hatemi, H. Yazici. Rheumatology, Istanbul University, Cerrahpasa, Istanbul, Turkey

Background: The quality of statistical analysis and reporting are wanting even in our most prestigious journals. ${ }^{1}$ It stands to reason that active participation of biostatisticians in data analysis and reporting would improve the situation.

Objectives: We aimed to test the hypothesis that more close cooperation with biostatisticians would improve the quality of reporting randomised clinical trials in rheumatology. We defined a close cooperation as the inclusion of a formal biostatistician among the co-authors and/or a declaration of formal statistical help in the study reports.

Methods: Two independent observers screened both by reading and, when applicable, electronic scanning the texts of all randomised controlled trials (RCT) in Annals of the Rheumatic Diseases, Arthritis Care and Research, Arthritis and Rheumatology, Rheumatology Oxford published in 2015 and 2016. Using a prepared worksheet, the observers specifically tabulated, the presence of a biostatistician among the co-authors and/or formal acknowledgement of statistical help in the methods, the inclusion of effect sizes (whether they were specifically indicated as such, could be calculated or not given at all) and the corresponding confidence intervals. The instances in which an effect size was given as a number needed to treat (NNT) and number needed to harm (NNH) were separately sought. In addition at the number of times separate $p$ values were reported for interdependent comparisons (like DAS28-CRP and DAS28-ESR), and the presence of a Bayesian analysis in the methods.

Results: The total RCT number in these four journals was 134 . In 26 trials, there was a biostatistician or an epidemiologist as a co-author and in 3, statistical help was acknowledged in the text. In the remaining 105 papers (78\%) no statistical help was declared. The tabulation of effect sizes, confidence intervals and giving separate $p$ values for interdependent variables are given in the table 1 . In giving the effect sizes it is to be noted that the presence of a statistician made did not improve the explicit announcement of an effect size but made it more calculable. None of the trials used Bayesian methods for analysis. Only in one trial NNT and in another NNH (both with no acknowledged biostatistical help) were given.

Abstract AB1387 - Table 1. The differences of the parameters between two groups

\begin{tabular}{|c|c|c|c|}
\hline & $\begin{array}{l}\text { Group } 1(n=29) \\
\text { (with } \\
\text { statistician) }\end{array}$ & $\begin{array}{c}\text { Group } 2(\mathrm{n}=105) \\
\text { (without } \\
\text { statistician) }\end{array}$ & $\begin{array}{c}\text { Calculated effect size } \\
\text { between the Groups } 1 \\
\text { and } 2\end{array}$ \\
\hline Effect size reporting, n (\%) & $26(90)$ & $61(58)$ & $\begin{array}{c}32 \%(95 \% \mathrm{Cl} 13.1- \\
43.3) \mathrm{p}=0.001\end{array}$ \\
\hline Given directly, $n$ (\%) & $2(7)$ & $5(5)$ & \\
\hline $\begin{array}{l}\text { Can be calculated (given } \\
H R, O R, R R, B \text { coefficient), }\end{array}$ & $24(83)$ & $46(44)$ & \\
\hline $\begin{array}{l}\text { Confidence intervals } \\
\text { reporting, } n(\%)\end{array}$ & $16(55)$ & $43(41)$ & $\begin{array}{c}14 \%(95 \% \mathrm{Cl}-6-32.7) \\
\mathrm{p}=0.18\end{array}$ \\
\hline $\begin{array}{l}\text { Calculating } p \text { values for } \\
\text { interdependent variables, } n \\
\text { (\%) }\end{array}$ & $14(48)$ & $46(44)$ & $\begin{array}{c}\begin{array}{c}4 \%(95 \% \mathrm{Cl}-14.9- \\
23.9) \mathrm{p}=0.67\end{array}\end{array}$ \\
\hline
\end{tabular}

Conclusions: The inclusion of a biostatistician improved the reporting of effect sizes, at least rendering them calculable. The same cannot be said for reporting confidence intervals and separate $p$ values for interdependent variables. It was interesting that Bayesian analyses and giving NNT and NNH, rather intuitive ways of expressing effect sizes, were not popular. There were 2 main limitations. The sample size was relatively small and many authors could have obtained statistical help without acknowledging it.

\section{REFERENCE:}

[1] Chavalarias D, et al. JAMA. 2016,315(11):1141-8

Disclosure of Interest: None declared

DOI: 10.1136/annrheumdis-2018-eular.6561

\section{AB1388 LIFESTYLE IN PATIENTS WITH SYSTEMIC LUPUS ERYTHEMATOSUS AND METABOLIC SYNDROME. INTERVENTION TO EXPLORE SELF-KNOWLEDGE, PERCEPTION AND IMPROVEMENT}

1. Etchegaray Morales ${ }^{1}$, M. Garcia Carrasco ${ }^{1,2}$, A. García-Villaseñor ${ }^{3}$, S. MéndezMartínez ${ }^{2}$, Á. Montiel. Jarquín ${ }^{2}$, N.E. Alonso García ${ }^{4}$, E. Jiménez Herrera ${ }^{2}$, P. Soto Santillan ${ }^{1}$, J.L. Gandara Ramirez ${ }^{5}$, C. Mendoza Pinto ${ }^{2} .{ }^{1}$ Department of Rheumatology and Immunology, Medicine School, Benemérita Universidad Autónoma de Puebla, Puebla, Mexico; ${ }^{2}$ Systemic Autoimmune Diseases Research Unit, General Regional Hospital No. 36, Instituto Mexicano del Seguro Social, Puebla, Mexico., Systemic Autoimmune Diseases Research Unit, General Regional Hospital No. 36, Instituto Mexicano del Seguro Social, Puebla, Mexico; ${ }^{3}$ ARTHIL Institute, ARTHIL Institute; ${ }^{4}$ departament of Psychology; ${ }^{5}$ Medicine School, Medicine School, Benemérita Universidad Autónoma de Puebla, Puebla, Mexico., Puebla, Mexico

Background: Lifestyle in patients with systemic lupus erythematosus and metabolic syndrome. Intervention to explore self-knowledge, perception and improvement.

Ivet Etchegaray-Morales ${ }^{1}$, Mario García-Carrasco ${ }^{1,2}$, Arturo García-Villaseñor ${ }^{1,3,4}$, Socorro Méndez-Martínez ${ }^{2}$, Álvaro Montiel Jarquín ${ }^{1,2}$. Norma Edith Alonso García ${ }^{5}$, Erick Jiménez Herrera, Pamela Soto Santillán ${ }^{1,2}$, José Luis Gándara Ramírez ${ }^{1}$, Claudia Mendoza Pinto ${ }^{1,2}$

${ }^{1}$ Medicine School Benemérita Universidad Autónoma de Puebla, Puebla, México.

${ }^{2}$ Systemic Autoimmune Diseases Research Unit, Instituto Mexicano del Seguro Social, Puebla, Mexico

${ }^{3}$ ARTHIL Institute

${ }^{4}$ Universidad de las Américas Puebla, Puebla, Mexico.

${ }^{5}$ Department of Psychology, Medicine School Benemérita Universidad Autónoma de Puebla, Puebla, México.

Summary: Systemic lupus erythematosus (SLE) has been associated with cardiovascular disease and metabolic syndrome (MS). A supportive educational intervention to modify lifestyle could improve morbidity and mortality in SLE patients with MS.

Objectives: To measure the impact of an educational intervention that improves the knowledge about disease and lifestyle in SLE patients with MS. 